\title{
ESTO NO ES UN TESTIMONIO...
}

\author{
Thomas Harris \\ Universidad Finis Terrae \\ principe.prospero@gmail.com
}

...sobre Nicanor Parra, debería continuar el enunciado del título, pero tal como está se da un aire más magrittieno, artista al que cada vez que visito, en sus múltiples y heterogéneas facetas, me recuerda o se me aparece Parra. No digo que sea uno de sus "predecesores" en el sentido del célebre ensayo de Borges sobre Kafka, pero algo de eso hay: por la desmesura rupturista, por su modernidad tan feroz como inteligente, por, finalmente, no dejar objeto cultural sacro sin sacarle hasta la última médula de lo sacro, desmantelarlo digamos derridarianamente, pero aún así guardar por él una suerte de admiración y empatía incomprensibles. O sea que si hay un artista del siglo XX que más me recuerda a Parra es Magritte. Lo digo sin temor a equivocarme, y también sin muchos argumentos que esgrimir acá, dado que este no es un texto que tienda a la demostración teórica sino al testimonio que no es, es decir al aprecio (etimológicamente) equívoco y escrito, no por la obligación de su cumpleaños número 100, sino porque sin Parra no seríamos, y creo que sin Magritte, tampoco. No me extenderé por lo tanto en las analogías que son múltiples y tal vez obvias, porque cité a Magritte más que nada por darle un título a este testimonio que no es una pipa. Ni Un desnudo bajando una escalera, ni Un gran vidrio ni tampoco una Fuente que es un urinario en el Louvre, porque siguiendo la lógica borgiana de los predecesores se me aparece también Duchamp, con una cercanía apabullante a Parra. Eso no quita ni suma. Solo relaciona en mi recepción ya tardía, en este su centésimo cumpleaños de Parra. Digo por la lucidez y la ferocidad que implica la modernidad de los dos artistas citados y su alcance más allá de su propia, o supuesta específica práctica del arte. Pero como esto no es un testimonio sobre Parra, trataré de que este escrito se acerque lo más posible a lo que no es. Un testimonio, tal vez, debería comenzar diciendo conocí a Parra...¿¿Lo conocí? La verdad es que creo que no, aunque estuve tres veces con él, una en su casa de La Reina, en una ocasión de la visita de la escritora sueca Sun Axelsson, que detestan los más irredentos parrianos, porque le atribuyen la culpa de que Parra no haya obtenido el Nobel - cosa falsa de falsedad absoluta como decía Lihn del mundo lárico de Teillier, cosa a la que tampoco adscribo- porque en esa oportunidad me di cuenta de que entre ambos había una empatía que no se había disuelto con los años. Tampoco me extenderé en esto: en cuestión de amores y otras 
intimidades como esas no va este testimonio: la cosa es que estuve esa vez en la casa de La Reina con Parra: debo decir que fue por el año 91, quizá, confío todo lo que venga en adelante a mi pésima memoria, mala cuestión para un testimonio pero bueno para "Esto no es un testimonio". O sea tenía como 34 años, venía llegando de Concepción, había publicado un libro que me dio cierta "figuración" en la chilena poesía, y en un momento estaba ahí, en La Reina, solos, face to face con el ati-poeta. Y hablamos. La verdad es que sabía que estaba conversando, con una desenvoltura terrible - por su partecon uno de los más grandes e inteligentes poetas no solo de Chile, sino de Hispanoamérica, y del Mundo. Eso es complicado. No por tratar de demostrar que eres capaz de hablar vis a vis con alguien que para mí siempre fue un mito viviente, sino por la fluidez y empatía con que se dio la conversación, que ciertamente trataba de poesía, y donde yo tenía que casi "presentarme", pero con la compañía de mi mujer Teresa Calderón y la misma Sun Axellson, que relajé y fue una charla bajo los árboles de esa casa centenaria y alejada del mundanal ruido y, creo, sí recordar bien qué hablamos, fue una conversa por decirlo en chileno, de poeta a poeta, y lo más asombroso y estimulante de todo, que nadie -ni Parra por ser quien era ni yo por ser un porque "joven" que tenía que demostrar lo que todo poeta joven se siente obligado a hacer ante un grande, fue una amena, estimulante, dialéctica y grata conversación a eso de las tres de la tarde. Le regalé mi libro recién publicado, Cipango, que diz los que poco me quieren -o los que más- es el único libro que interesa de mi obra; después Nicanor desapareció de mi memoria de ese día. No lo volví a ver hasta una encuentro en su casa de Las Cruces, años más tarde. Creo que la ocasión fue un encuentro por algún, también, aniversario de algo de Huidobro, tal vez en 1993, porque por motivos que huelgan especificar acá, yo no estaba bebiendo alcohol. Un dato para la memoria. Estábamos con Teresa Calderón, mi mujer, y creo que entre los otros contertulios se hallaban Enrique Lafourcade, Ana María Larraín, Diamela Eltit, una chica joven que no logro recordar quién era y mi amigo Federico Schopf. Ahí hablé más largo y tendido y relajado con Nicanor Parra, y en un momento en que quedamos solos, que es la mejor manera de conversar entre poetas, si se me permite el dislate, me habló de Cipango... en términos muy halagüeños, pero lo que más me sorprendió fue una pregunta, que, bueno, ahora, no me sorprendería para nada: “En qué estado escribiste ese libro fenomenal?"; la pregunta es textual de eso sí me acuerdo y no es por egotismo, sino por la pregunta en sí, es decir, en el fondo, con qué substancia, o en qué alterado estado había concebido el libro. Le respondí que con vino y mariguana, pero que no lo había escrito bajo el influyo del alcohol y la droga, sino que lo había "concebido" así. Que no podía -y no puedo y no se puede- escribir en estados alterados, pero sí observar el Mundo y atesorar esa "visiones" en la memoria y el imaginario, para escribirlas más tarde. Pero dejo hasta aquí mi experiencia vital con Parra, para pasar a la otra, igual de vital que es la recepción, la lectura y lo que ella dejó en mí, y también en mi escritura, dos caras de una misma moneda. Como un eco quedó en mi lectura retrospectiva su interés por la alteración de la conciencia en la escritura. O sea vi en Parra, más aun que el poeta inteligente, lúcido, trasgresor, y el poeta que simplificó el lenguaje, para llevarlo a eso que se ha dado en llamar el discurso de la tribu, supongo el de la tribu de la chilenidad, cosa bastante vaga, dado que no hay poesía más lateral y oblicua que la de Parra y su intento de dar voz a un país, o más bien al ethos de un país que él mismo 
advierte es más bien un "paisaje": la ironía, lo sabemos, no es inocencia, ni claridad, sino lo opuesto, una opacidad perversa, incluso un tanto cruel, por mor de la ironía, procedimiento literario que comienza a desplegar sus fueros por allá por el siglo VXIII, con Novalis, la escuela de Jena, y una forma de percibir el mundo, si bien con un yo desmesurado, con la incorporación a la lírica de aspectos casi parrianos como la conciencia de la muerte, la ironía ante esa conciencia, el absurdo existencialista, el humor negro del que hablaba Breton, ciertas formas de incorporación del amor en tanto erotismo y el habla oral, popular, que los alemanes prerrománticos rescataron de lo "popular" para ingresarlo al estatuto de lo lírico. No hay tanta distancia de los Cantos de la experiencia de Blake, transparentes e irónicos, populares y reivindicativos, del proyecto parriano, por decir algo. Y Shakespeare. Y los mismos simbolistas franceses: el golfo que representaba Rimbaud (el que amaron los beat) y, sobre todo, el coleccionista de restas o restos de la sociedad capitalista que comienza en el Segundo Imperio, el flaneur baudeleriano, tal como lo lee Walter Benjamin, el poeta que hace esa suerte de pesca de arrastre de todos los decires de su época, que no son otros que los decires que deja como el habla moderna de los traperos, los alcohólicos, las putas, los alucinados, los mendigos, toda esa oralidad que desdeña la burguesía naciente y que el flaneur, tal poeta, recoge sin rasero, sin privilegios ni jerarquías: ¿no hay algo o mucho de esa modernidad, citacional sin escalafones en la más radical modernidad de Parra? ¿Desde sus Poemas y antipoemas, pasando por los Artefactos, hasta las Prédicas y sermones del Cristo de Elqui? Parra, no solo recoge estas restas, sino que además las rearticula con la poesía considerada como "superior" en su tiempo -vanguardias incluidas- y las combina en un mismo estatus, con, por ejemplo sus aluciones a Wittgenstein o Aristófanes en sus textos más programáticos o metapoéticos. De allí la chilenidad, innegable, e incluso, inaugural, de Parra: un poeta que narra Chile, que se abisma en sus instancias más oscuras, intersticiales e indecorosas: no por nada, creo, Raúl Ruiz le dedicó su película más “chilena”, Tres tristes tigres -para mí su mejor cinta-, tanto como al Colo-Colo - del cual uno de los tantos hablantes de Parra aspira a ser Presidente- y a Joaquín Edwards Bello, al que una lectura atenta y comparada, encontraríamos muchos aspectos en común con Nicanor Parra. Como también los tiene Parra con Neruda. Dos poetas que leí a los 16 años, y no se me contraponían sino complementaban. Como afirma con la lucidez que le es tan característica, el poeta Roberto Merino me aclara este punto en su artículo "Las lechugas de Nicanor Parra": él afirma en ese artículo que hay una relación evidente entre ambos autores. La ve en la dilación de Parra en la publicación de sus Poemas y antipoemas, demora por la sospecha de que "no los sentía listos para enfrentar el dominio absoluto que la figura de Neruda ejercía en la poesía local". Pero, Merino nos recuerda que fue el propio Neruda uno de los primeros lectores y admiradores de Poemas y antipoemas, el año 1954, año también de la aparición de las Odas elementales. Libros para Merino muy distintos, a pesar de la "equívoca" lealtad o adscripción al "uso del lenguaje común de la poesía". Lo que ocurre con Parra y Neruda, concluye con una meridiana claridad o iluminación, es que en el caso de Parra no se trata de una simplificación del vocabulario y de las ideas. Porque si escribe sus poemas con el lenguaje de todos los días, el de la tribu o el de la calle, lo que hace en forma predominante es poner en escena sus mecanismos: oblicuidad, sugerencias veladas, la facultad de dar a entender antes de decir. "En Parra -concluye 
Merino- la chilenidad es estructural; en Neruda, una celebración didáctica”. Lo que significa líricamente, más allá del lenguaje ad usum, una diferencia de modo y actitud, en el ámbito de la modernidad, abismal. Como abismal es la diferencia, en su mismo tiempo y espacio, entre Baudelaire y Rimbaud, entre Withman y T.S. Elliot (El The West Land y consigo mismo, con el de Los cuatro cuartetos): la distancia que mediaría, si pensamos en Octavio Paz, entre la ironía romántica -desmesurada y disfórica- y la metaironía de la postvanguardia -más que una revolución una tentativa de restauración. pero, finalmente, ¿de qué?... ¿De que la poesía no es mensurable, no es pequeña ni grande -es poesía simplemente? ¿Pérdida o ganancia? ¿Artemisa como una chica pin up, o Artemisa una pin up?: la Tirana o la Alessandra Mussollini de Diego Maquieira; las muchachas buenasmozas mostrando sus blancos calzones de Claudio Bertoni; las chicas violadas con una rata en la vagina de Roberto Bolaño; la compañera masacrada por los militares de Raúl Zurita? ¿O esa muchacha rodeada de espigas que si no es la poesía, mejor que se acabe la película, mejor que se acabe la función? 